\title{
AS FONTES DE ESTRESSE EMOCIONAL QUE AFETAM A ENFERMEIRA NA ASSISTÊNCIA À CRIANÇA GRAVE*
}

\section{Edna Ikumi Umebayashi Takahashi**}

T AKAHASHI, E.I.U. As fontes de estresse emocional que afetam a enfermeira na assistência d̀ criança grave. Rev. Esc. Enf. USP., São Paulo, 19(1): 5.20, 1985.

No presente trabalho procurou-se obter o relato das situaçoes consideradas problemáticas por enfermeiras que atuam junto a crianças graves, através de entrevista semiestruturada. As informaçóes obtidas permitiram identificar como fontes extrinsecas de estresse emocional: $o$ contex to de Unidade de Terapia Intensiva (UTI) (ambiente e finalidade); os aspectos administrativos; a equipe de UTI; a familia e a condiço da criança. Como fontes intrinsecas identificou-se dado: a condiça pessoal do enfermeiro e alguns aspectos relativos a questao da morte. Com a descrição dessas fontes de estresse espera-se promover uma análise e reflexao sobre aspectos da prática do enfermeiro que atua em Unidade de Terapia Intensiva Pediátrica (UTIp), para reestruturaçăo dessa prática.

\section{INTRODUÇÃO}

$\mathrm{Na}$ tentativa de melhorar a assistência ao doente criticamente enfermo, foram criadas em nosso meio, na década passada, as unidades de cuidados intensivos, onde os recursos humanos e materiais são adequados para o tratamento desses pacientes. Posteriomente, devido ao número de crianças hospitalizadas por enfermidades graves ou potencialmente graves, fez-se tambem necessário destinar áreas especf́ficas do hospital à assistência a essas crianças criticamente enfermas. Nesses locais, a assistência de enfermagem é bastante complexa, não somente por exigir habilidade no manuseio de equipamentos especializados e execução de procedimentos especificos, como também por envolver um ser humano tão vulnerável e frágil do ponto de vista físico e psicologico, como o é a criança.

A instabilidade das funçōes fisiológicas da criança, o trauma decorrente da separação dos pais e o contato com ambiente e pessoas estranhas aumentam a problemática da assistência à criança grave.

Nesse contexto de assistência, pela própria exacerbação dos problemas

* Trabalho apresentado no 1 \% Encontro Brasileiro de Enfermagem de Terapia Intensiva Pediátrica.

* Enfermeira. Mestre em Enfermagem. Professor Assistente do Departamento de Enfermagem Médico-Cinúrgica da Escola de Enfermagem da USP - disciplina Enfermagem Médico-Cirurgica. 
emocionais tanto das crianças como de seus familiares, torna-se essencial uma abordagem mais humana pelas pessoas da equipe que atuam junto a esses doentes.

Segundo CARNEIRO ${ }^{2}$, dentre os profissionais de saúde, os da equipe de enfermagem são os que têm maior responsabilidade na humanização da assistência, não só pelo número de pessoas nela envolvidas, como pela sua permanência contínua ao lado do paciente.

Assim sendo, a responsabilidade da assistência à criança grave e à sua famflia depende da capacidade da enfermeira de identificar e valorizar as necessidades especiais de pessoas em crise e selecionar os componentes necessários para essa assistência. Pela utilização de recursos pessoais a enfermeira pode compreender o paciente e sua família e juntos buscar soluçoes para as situaçôes problemáticas vividas. Assim, a compreensão se torna um instrumento essencial para uma abordagem humanizada do paciente pela enfermeira. No entanto, $o$ ato de compreender a si própria e dqueles a quem se assiste deve levar a enfermeira à análise e reflexão das situaçðes vivenciadas.

Para CAPALBO ${ }^{1}$, o homem só poderá compreender a si mesmo se tiver a percepção de sua totalidade tal como ele existe realmente.

Assim, a percepção pela enfermeira de UTIp de sua atuação torna-se indipensável principalmente por esta implicar na assistência a pessoas em momento de crise.

Acreditamos que a análise e reflexão pela enfermeira de UTIp sobre algumas questбes que defronta em sua atuação no dia a dia servirão de base para a compreensão das situaçðes concretas vivenciadas que constituem a sua existência pessoal e profissional.

\section{Objetivos}

Considerando que,

- atuar em UTIp implica em vivenciar situaçðes concretas que podem influenciar ou ser influenciadas pelo sentir, pensar e agir da enfermeira;

- a reflexão do cotidiano pela enfermeira de UTIp é o fundamento para maior compreensão das situaçðes concretas vivenciadas;

- a ação da enfermeira depende da percepção da sua realidade de vida e da sua vivência profissional;

traçamos, por objetivo,

- identificar que situaçðes, na atuação diária da enfermeira de UTIp, são consideradas como fontes de estresse emocional; 


\section{METODOLOGIA}

Natureza do estudo

O presente trabalho representa uma tentativa de aplicar no campo da enfermagem hospitalar, especificamente em UTIp, um modelo de investigação alternativa.

Trata-se de teste piloto de um estudo qualitativo, onde se buscará a descrição das situaçðes de estresse vivenciadas por enfermeiros de UTIp. Alguns dados quantitativos serão apresentados para complementação.

\section{Coleta de dados}

Para o presente estudo optou-se pela utilização de entrevista individualizada, semi-estruturada. Essa entrevista foi realizada com treze enfermeiras que atuam em três Unidades de Terapia Intensiva Pediátrica (UTIps) de um hospital governamental.

A entrevista tinha como tema central a percepção das enfermeiras quanto às situaçóes de estresse emocional na sua vivência diária junto a criança grave. A mesma questão foi sempre colocada, inicialmente, para cada enfermeira e outras perguntas foram sendo inclurdas a medida que o diálogo se desenvolvia.

\section{Categorização dos dados}

A análise individual das entrevistas permitiu identificar diferentes situaçðes consideradas problemáticas, pelas enfermeiras, na atuação diária junto a crianças graves. Após a transcriçăo de trechos do diálogo nos quais a enfermeira descrevia essas situaçóes problemáticas, foram relacionados, em grupos, todos os problemas mencionados de acordo com o tema envolvido.

\section{RESULTADOS E COMENTÁRIOS}

\section{Perfil das enfermeiras}

As 13 enfermeiras do presente estudo são de sexo feminino, sendo 10 solteiras e 3 casadas. A idade variou de 22 a 35 anos, sendo 3 de 22 a 25 anos, 8 de 26 a 30 anos e 2 de 31 a 35 anos. A maioria (11) tinha mais de 3 anos e meio de formada e o tempo de atuação em UTIp, variou de 5 meses a 5 anos, sendo que 8 enfermeiras trabalham há mais de 2 anos, 4 de 1 a 2 anos e apenas 1 com menos de 1 ano.

Por se tratar de modalidade alternativa e pouco utilizada de coleta e registro de dados, isto é, entrevista com questóes abertas e gravação, foi evidente, no inf cio das entrevistas, a observaçăo de tremor na voz, espera de aprovação 
em face de algumas colocaçð̃es, modificação constante de postura, respostas breves e curtas.

À medida, entretanto, que a entrevista transcorria, foi possivel perceber situação de relaxamento onde comentários comicos e risadas se sucederam. Por outro lado, durante o relato de situaçóes mais emotivas, foi comum o brilho e lacrimejamento dos olhos das entrevistadas.

Notou-se, ainda, o envolvimento das enfermeiras entrevistadas com a modalidade da assistência prestada. Todas, sem exceção, declararam gostar, no momento, de atuar junto a crianças graves, o que, para algumas, no início, foi motivo de muita dificuldade.

\section{Fontes de estresse}

Foi possivel, através desta estratégia de coleta de dados, obter a descrição de situaçбes consideradas estressantes pelos entrevistados. Foram estas relacionadas a: - características de atendimento da unidade; - ambiente físico da UTIp; - condiçбes de trabalho; - atividades desempenhadas pela enfermeira; • equipe de enfermagem; - equipe médica; - reação emocional da famflia; - envolvimento emocional da enfermeira com os pais; - desempenho profissional junto à família; - necessidades da criança grave; - conhecimentos e habilidades em procedimentos; - integração dos valores pessoais e profissionais; - coerência entre ação e reação da enfermeira; e, • atitude da enfermeira diante da morte.

Através da relação inicial dos diferentes grupos de problemas foi possível, ainda, associá-los entre si, constatando-se que são, basicamente, problemas relativos ao contexto de UTI, aos seus aspectos administrativos, a equipe de UTIp, a famflia, à condição da criança, à condição pessoal do enfermeiro e à morte.

Analisando-se a totalidade das informaçðes obtidas, foi possivel verificar que, "grosso modo", poderiam ser classificadas em fontes extrínsecas e intrínsecas de estresse.

As fontes extrínsecas, por abrangerem primariamente situaçðes problemáticas decorrentes de condiçoes externas à pessoa do enfermeiro, incluem aquelas relativas ao contexto de UTI, a aspectos administrativos, à equipe de UTI, a família e à condição da criança. As fontes intrínsecas referem-se a problemas conseqüentes, primariamente, de inadequada compreensão e aceitação desses problemas pela própria enfermeira de UTIp, englobando assim as questбes relativas a morte e a outras condiçסes pessoais.

\section{Contex to de UTIp}

Analisando-se estas referências apontadas por 12 enfermeiras podem elas 
ser classificadas em dois grupos: um relativo às características de atendimento da unidade (finalidade) e o outro, ao ambiente f́sico.

\subsection{Caracteristicas de atendimento da unidade}

Neste grupo foram consideradas estressantes as situaçoes que implicavam em atendimento de emergência (7) e que foram assim relatadas: "situaçסes não esperadas são muito estressantes, as coisas acontecem sem você saber e sem estar esperando", "não dá tempo de preparar material, corre, pega emprestado"; "muita gente, não dá para coordenar atendimento na parada". Além das situaçoes de emergência foram considerados como problemas: várias coisas a serem feitas ao mesmo tempo (3); o rítmo intensivo na prestação de cuidado (2); a unidade super especializada (1) e a variação de ritmo, por vezes calmo e por vezes agitado (1).

A análise de todas estas colocaçóes nos permite compreender melhor alguns aspectos inerentes d UTIps. Nestes locais, independentemente das diferenças quanto ao tipo de instituição, à estrutura física da unidade e d equipe que nela atua, algumas características são comuns. Os pacientes internados nessas unidades são crianças gravemente enfermas e sujeitas a inúmeras intercorrências e a situaçoes de emergéncia devido às próprias condiçōes fisiologicas alteradas. Em virtude de abarcar procedimentos dignósticos e terapêuticos especificos ao tratamento dessas crianças, criticamente doentes, e da necessidade de ter uma equipe devidamente preparada para a assistência intensiva, a unidade é quase sempre caracterizada como "super especializada"; entretanto, nem sempre o ponto de referéncia para tal caracterização tem sido a tecnologia empregada nessas unidades e sim a propria necessidade de cuidados diretos, intensivos e contínuos às crianças internadas. Apesar da atuação da enfermeira em área hospitalar não estar sendo caracterizada pela sua participação na assistência direta aos pacientes, este fato parece não interferir na caracterização das UTIs como locais onde a presença do enfermeiro tem se tornado fundamental para uma assistência qualificada.

A participação das enfermeiras na assistência direta intensiva às crianças graves e as particularidades exigidas para tal assistência é que parecem caracterizar as UTIps como "super especializadas".

\subsection{Ambiente fisico}

Três mençōes foram feitas considerando imprópria a estrutura física das UTIps. O ambiente fechado e isolado (2) foi referido como favorecedor de rixas e dificuldades no relacionamento entre os elementos da equipe de enfermagem por desencadear estresse; o fato de não existir área de isolamento em algumas UTIps e a necessidade de muitas vezes ser necessário improvisar tal área também foram mencionados (1).

Em literatura, se pouco tem considerado o ambiente físico como fonte 
de estresse para o enfermeiro, talvez pelos outros problemas se sobressairem em relação a este; entretanto, KIMURA ${ }^{4}$, em estudo comparativo sobre a percepção de enfermeiras e pacientes de UTI, quanto aos problemas sentidos por estes últimos, verificou que ambos consideram o ambiente como problema para o paciente, tendo o enfermeiro dado maior importância a este problema que o próprio paciente.

Apesar de diferentes conceituaçбes de ambiente serem analisadas em diversos estudos, parece ser comum a todos a relação estreita dos efeitos psicológicos desses ambientes com os conceitos preconizados. Em nosso estudo pouco foi mencionado, parecendo, pois, não ser o ambiente um dos problemas mais sentidos pela enfermeira de UTIp. Entretanto, é interessante notar que as enfermeiras que atuam em UTI geralmente referem ter preferência por essas unidades, não só pelo fato de nelas prestarem assistência direta ao paciente como tamberm, pelo fato do ambiente ser menor e, portanto, favorecer maior domínio ou controle da situação global.

\section{Aspectos administrativos}

Sete enfermeiras fizeram referências a problemas de ordem administrativa relacionados a: condiçoes de trabalho, atividades desempenhadas e aspectos institucionais.

\subsection{Condições de trabalho}

Neste item, as seguintes colocaçðes foram consideradas: "sobrecarga de trabalho por falta de pessoal" (5); "doze horas em UTI é muito cansativo, pois geralmente falta pessoal e ocorre de tudo" (2); "grande rotatividade no horário não permitindo ter vida própria" (1); "trabalhar por muito tempo em UTIp" (1); "férias uma vez por ano é pouco" (1).

Esses comentários nos permitem ressaltar a importância de prover as UTIps de recursos humanos adequados, não somente do ponto de vista qualitativo como também do quantitativo. Tem-se constatado que a grande maioria das UTIs tem procurado contar com enfermeiras em todos os seus plantठ̄es, seja para prestação de cuidados diretos seja para supervisão da assistência prestada pela equipe de enfermagem. Na nossa opinião isto tem garantido, de certa forma, a qualidade da assistência de enfermagem prestada nas UTIs. No entanto, a qualidade dessa assistência não pode ser assegurada quando existe sobrecarga de trabalho por falta qualitativa e quantitativa de pessoal.

Além disso, é preciso que a instituição adote uma política de trabalho na qual seja valorizado o aspecto humano do próprio profissional. Desta forma, há maior probabilidade de boa qualidade da assistência ser assegurada, o que traria benefícios para a criança, a família e a instituiçðo. 


\subsection{Atividades desempenhadas}

Dentro desta categoria foram considerados os problemas relacionados às atividades desempenhadas pelas enfermeiras nas UTIps. Assim, citaçסes como "Além de cuidar das crianças, o desempenho de atividades administrativas sobrecarregam e estressam" retratam a referência de 4 enfermeiras quanto ao desagrado em executar atividades burocráticas e/ou administrativas. Uma dessas enfermeiras foi categorica ao comentar que "enfermeira burocrática é sempre enfermeira estressada". Outras citaçðes foram incluídas: "falta de função definida, muita função que não é sua" (1), "quanto maior a responsabilidade pela parte administrativa, maior é a dor de cabeça; tem-se que atender a várias coisas" (1).

O desempenho de papel administrativo tem exigido da enfermeira o envolvimento com atividades burocráticas. De certa maneira, a sua formação profissional tem favorecido a atribuição de valor maior ao aspecto assistencial, o que vem reforçar a não priorização das atividades administrativas e consequèentemente burocráticas. Além disso, o interrelacionamento entre funçóes administrativas e assistenciais dificultam a analise mais objetiva sobre a especificidade das funçôes que caberiam à enfermeira.

Nas UTIs, a participação da enfermeira conjuntamente à de outras categorias da enfermagem na assistência direta ao paciente crítico também tem sido fonte de dificuldade na definição das funçбes espeçficas da enfermeira. Essa não delimitação de funçoes vem possibilitar dúvida sobre a responsabilidade da classe em fazer com que a esséncia da enfermagem transpareça nas ações da enfermeira.

\subsection{Outros aspectos institucionais}

Foram inclurdas, aqui, mençóes quanto a: "falta de preocupação da instituição em colocar a enfermeira sem preparo prévio" (1); "não valorização da parte humana da enfermeira pela instituição" (1).

O treinamento em serviço tem sido usualmente preconizado na admissão de enfermeiros para UTIs; no entanto, o perfodo estipulado para esse treinamento nem sempre parece suprir as necessidades sentidas pelas enfermeiras, o que pode gerar insegurança na fase inicial de sua atuação junto a pacientes críticos. Além disso, pelos depoimentos das entrevistadas, parece ser fato que vários cursos de graduação em enfermagem não preparam os alunos para atuarem nessa área especializada.

\section{Equipe de UTI}

Doze das treze enfermeiras entrevistadas fizeram referência a problemas relacionados à equipe que atua em UTIp. Esses problemas foram agrupados em situaçoes referentes a: equipe de enfermagem (6); equipe médica (8) e a outros elementos da UTI (1). 


\subsection{Equipe de Enfermagem}

Vários aspectos relativos à equipe de enfermagem foram levantados como fontes de estresse. $O$ mais frequente deles está relacionado à existência de diversos graus hierárquicos na enfermagem, favorecendo a manutenção de uma atitude exigente entre as próprias enfermeiras e pouca autoridade da enfermeira de cabeceira perante seu funcionário, o que pode ser exemplificado pelas citaçסes: "muita hierarquia na enfermagem, muita chefe; perde-se a autoridade frente aos funcionários"; "... outras enfermeiras cobrando, muita hierarquia ...".

De certa forma constata-se que a existência de diferentes níveis hierárquicos na enfermagem reflete a influencia do sistema funcional, no qual cada elemento tem funçסes especificas, de acordo com o nível que ocupa, e poder de decisão correspondente a esse grau hierárquico; assim, as enfermeiras de UTI que atuam direta e constantemente ao lado dos pacientes estáo subordinadas a outras enfermeiras que ocupam um ou mais cargos superiores; entretanto, essas mesmas enfermeiras "de cabeceira" têm maior autoridade que o pessoal das outras categorias da enfermagem.

A falta de autoridade relatada por algumas enfermeiras pode, entretanto, ter como cau sa não só o seu pouco poder de decisão em determinaçôes mais amplas como também a frequente não diferenciação entre as funçōes exercidas pela enfermeira e as exercidas pelas demais categorias de enfermagem.

Em relação aos funcionários foi citada por uma enfermeira, como fato de estresse, a presença de elementos pouco responsáveis, principalmente por se tratar de assistência a crianças graves. $O$ desequilíbrio emocional dos funcionários, em conseqüência de fatores diversos aos quais eles também estão submetidos por atuarem em UTI, também foi citada como fonte de estresse para a enfermeira.

Outra questão mencionada foi a desunião e a competição existente entre as proprias enfermeiras, dificultando o relacionamento, a troca de experiências e o crescimento profissional.

A falta de uma linha comum de atuação mencionada por uma das entrevistadas parece ter importância fundamental para a enfermagem. Cabe aqui ressaltar que a definição de uma linha filosófica se faz necessária em todos os níveis de atuaçao da enfermeira, a fim de tornar o seu trabalho coerente com as crenças e valores profissionais. Com essa prática, baseada em valores comuns, acreditamos tornar-se possivel a consolidação do corpo de conhecimentos de enfermagem.

\subsection{Equipe Médica}

Com relação à equipe médica constata-se que as questóes básicas referem-se à dificuldade de relacionamento principalmente pela tendéncia do médico 
em manter-se em uma posição hierarquicamente superior à enfermeira e pela inexistência do trabalho e espírito de equipe. Sabemos que muitas funçðes da enfermeira são dependentes da resolução conjunta com $\emptyset$ médico, mas que, no nosso meio, pelo proprio reflexo do papel social de cada um desses elementos, ainda ño são assim compreendidas. Mesmo nasiUTIs, onde a enfermeira, pelo seu preparo e desempenho, parece ser bastante valorizada pela equipe médica, há pouca discussão para uma resolução conjunta; mais ainda, existe cobrança das ações de enfermagem por parte do médico; no entanto, essa exigência não parece estar vinculada à falta de confiança, e sim ao fato de ser necessária a execução rápida dessa ação. Em uma das unidades, onde há participação de outras categorias de pessoal de enfermagem na prestação de cuidados, foi mencionado que as exigências dos médicos quanto às açð̃es de enfermagem passaram a ser maiores com a introdução desses elementos na assistência. Essa atitude do médico, por outro lado, reflete em atitude semelhante da enfermeira para com os elementos auxiliares da equipe de enfermagem, o que foi relatado por uma das entrevistadas. Essa situação, no seu conjunto, acaba refletindo o sistema social, anteriormente comentado, onde se denota o poder daquele que ocupa a melhor posição dentro da escala hierárquica formal ou informalmente estabelecida.

A solicitação contínua do médico junto à enfermeira, foi também mencionada como fator de estresse. Conforme rela tado, todas as solicitaçбes são feitas à enfermeira, desde aquelas sobre falta de material até as referentes a alguns aspectos da assistência. Tal fato é decorrente do próprio papel administrativo desempenhado pela enfermeira e sua conseqüente responsabilidade pelo bom funcionamento da unidade.

Ainda em relação à equipe médica, foi mencionado que, pelo fato da UTIp ser de hospital-escola, há presença constante de médicos novos cuja "insegurança nas situaçðes de emergencia" e "desconhecimento do serviço", sobrecarregam a enfermeira, causando estresse. São situaçóes esperadas, pela própria característica de se tratar de hospital-escola, que parece ser compreendida pela enfermeira.

\subsection{Outros elementos}

Dentre os outros elementos que atuam na UTI, foi lembrada da importância de haver escriturários competentes, pois, quando tal fato não ocorre, há sobrecarga para a enfermeira.

Isto mais uma vez nos faz refletir que as enfermeiras, ao assumirem a responsabilidade pela assisténcia a pacientes de UTI, acabam se tornando os elementos-chaves para a melhoria da assistência, e portanto acabam sendo sobrecarregadas pela falta de outros.

\section{Familia}

Segundo DUNKEL \& EISENDRATH ${ }^{3}$, apesar de existirem numerosos 
meios no qual a equipe se beneficia com a presença da família, os familiares podem ser a causa de estresse psicológico. No presente estudo, onze enfermeiras teceram comentários referentes a faḿlia como fonte de estresse. Assim, foi possível agrupar fatores de estresse emocional relacionados a: reação emocional da familia, envolvimento emocional com a família e trabalho profissional com a família.

\subsection{Reação emocional da famtlia}

O aspecto mais relevante considerado pelas enfermeiras foi relativo às reaçסes de ansiedade, insegurança e agressividade dos pais, sendo "descarregadas na enfermeira e no médico"; ficou perceptível a compreensão da enfermeira perante tais reaçðes; no entanto, pouco foi dito sobre como ajudar a minimizá-las. A discussão sobre como a equipe "sente" os familiares e como certos familiares fazem os membros da equipe se sentirem, pode ajudar a equipe a manter sua objetividade na assistência ${ }^{3}$. Assim, a identificação, pela enfermeira, da reação emocional da família e sua compreensão e aceitação não poderiam se reduzir ou minimizar essa reação? Não seria dessa forma que equipe e família, estariam trabalhando por um fim comum - at recuperação da criança?

\subsection{Envolvimento emocional com os pais}

Várias enfermeiras referiam que, ao ver a mãe chorar, choram ou têm vontade de chorar tambem. Afirmaçðes como "é como se fosse um filho meu" denotam a identificação da enfermeira com a mãe da criança e frequentemente a crise de choro da mãe tem repercussão na própria enfermeira. Essa situação mencionada por algumas entrevistadas, desencadeia muita tensão, o que faz com que a enfermeira se contenha para não se envolver tanto.

Cabe aqui uma indagação. Não seria através do envolvimento, do compromisso e do enfrentar problemas juntos que estaríamos realmente "assistindo'?

\subsection{Desempenho profissional junto à familia}

Os problemas anteriormente referidos parecem estar muito vinculados às dificuldades expressas pela enfermeira de lidar com a família: "falta subsídios para apoiar", "ño saber o que falar quando a criança tem prognóstico fechado". Algumas vezes, o trabalho com a família nem sempre resulta em resposta desejada, o que pode ser verificado pelas seguintes expressరes: "A dificuldade maior é que eles não sentem a gravidade do problema. Não sabem o risco de vida, vocé fica sem saber se é por falha na orientação ou se eles não querem entender" ou "Explico a doença, de repente não se sabe se entendeu".

Toda essa dificuldade acaba tendo, como reflexo, consideraçðes negati- 
vas quanto à presença da família: "A família começa até a atrapalhar. É uma solicitação, um apoio que teríamos que dar naquela hora. Talvez porque não estejamos muito preparadas, de repente, não sabemos mais o que falar. As vezes, acabamos mais estressadas do que a própria família" ou "Para a enfermeira o horário de visita é diff́cil; é preciso dar atenção à família, além de fazer controles; fico inclinada a dizer que nao é bom ter visitas".

Outro aspecto aqui relacionado é a expectativa da família com relação ao desempenho do profissional, o que acaba de tornando um fator de sobrecarga emocional para a enfermeira, tal como é visto nos comentários: "A mãe chora e pede para não deixar a criança morrer" ou "Depositam toda a confiança no pessoal de enfermagem e no médico, o que me bloqueia um pouco, não sei como reagir'. Por outro lado, o próprio profissional relaciona algumas expectativas e sentimentos seus ao lidar com a família. "Tenho medo de receber a famflia, tirar a esperança dela" ou "Não posso cortar a ilusão dos pais". Notam-se, tambem, alguns pontos conflitantes para a enfermeira na sua atuação junto a família pelas afirmaçðes: "Não posso dar tudo que eles precisam e me sinto incapaz" ou "A enfermeira tem que se portar como profissional. Se chora parece que está sendo fraca".

\section{Condições da criança}

Dentre as mençðes relativas à condição da criança, foi possível relacionar situaçōes problemáticas, referidas por dez enfermeiras, sobre as necessidades da criança grave.

\subsection{Necessidades da criança grave}

Foi citado que o máximo de cuidado deve ser tomado para a assistência à criança, uma vez que tudo deve ser ministrado proporcionalmente ao seu tamanho e de que, quanto menor a criança maior é o estresse da enfermeira na prestação dos cuidados. Segundo uma das entrevistadas, a criança grave é indefesa e depende muito da enfermeira e de seus cuidados técnicos; exige muita atenção o tempo todo, muito habilidade técnica e conhecimento.

Como qualquer erro, por mais simples que seja, pode ter consequências sérias quando se trata de crianças, foi constatado, pela exposição das entrevistadas, que o nível de atenção redobrada das enfermeiras em UTIps podem ser fator de estresse.

Assim, uma causa de tensão para a enfermeira é a observação rigorosa e constante da criança grave. Algumas enfermeiras consideram que, por serem crianças que nåo falam, exigem da enfermeira muita atenção o tempo todo e constante observação pois qualquer sinal tem que ser decifrado.

$O$ fato de se tratar de crianças graves, que a qualquer momento correm o risco de uma emergência, foi manifestado por várias enfermeiras, o que já havia sido também associado ao contex to de UTIp. 
Foi também mencionada a descompensação da parte afetiva da criança de UTIp, citada apenas como constatação e não como problema desencadeador de estresse emocional.

\section{Condição pessoal da enfermeira}

Onze enfermeiras fizeram referencia a problemas relacionados à inadequada compreensão e aceitação pessoal como fatores de estresse, que permitiram sua classificação em problemas relativos a: conhecimentos e habilidades em procedimentos (5); integração dos valores pessoais e profissionais (5) e coerência entre ação e reação (6).

\subsection{Conhecimentos e habilidades em procedimentos}

A expectativa de que a assistência seja de alta qualidade, em UTI, aumenta ainda mais a responsabilidade da enfermeira. A assistência à criança grave exige conhecimentos e habilidades especiais. A falta desse preparo tem revertido em causas de estresse para enfermeiras na fase inicial do trabalho em UTIp. Das enfermeiras que fizeram referência a esse problema, apenas uma encontrava-se trabalhando havia pouco tempo: cinco meses; as demais citaram o problema porque o haviam considerado estressante na ocasião da admissão. Para uma das enfermeiras "somente depois que se tem segurança técnica é que se desenvolve o plano humano". Isto denota e reforça a necessidade de se trabalhar as fontes de estresse da propria enfermeira, identificar as causas de estresse para que ela possa livremente bem desempenhar o seu papel profissional, tanto técnico quanto humano. Resta aqui ressaltar o papel das Escolas no preparo de pessoal para atuação nessa área especifica.

\subsection{Integração dos valores pessoais e profissionais}

Algumas situaçбes conflitantes sđ̃o reveladas pelas enfermeiras, mostrando a falta de integração entre os valores considerados como pessoais e os profissionais. Assim, o seguinte comentário reflete tal conflito: "A fam ́lia mexe comigo como pessoa e não como enfermeira executando técnica" ou ainda, "Quando a família começa a chorar, temos que nos portar como profissional mas quando vemos que o outro está sofrendo ... Uma vez já chorei; mas, na maioria das vezes, não choro. Se chorarmos parece que estamos sendo fracas; chorando não vamos mostrar para a família que estamos lá para dar apoio. Ou será que chorando é que mostramos que estamos apoiando? Mas acho que ficamos naquela atitude mais passiva para não envolver e não causar tanta tensão. Nós nos contemos mais por isso".

Pelas declaraçбes parece claro que as funçбes do enfermeiro são relacionadas mais ao desempenho de atividades técnicas e que a reação emocional do enfermeiro só poderá ocorrer a nivel não profissional. $O$ fato de chorar parece ser encarado como atitude não aceitável, por dificultar, de alguma forma, a atuação profissional. Por esse motivo parece ser criada, por parte 
de algumas enfermeiras, resistência ao envolvimento com crianças e familiares. No entanto questionamos se não seria o caso de tentarmos controlar nossas respostas emocionais ao invés de abolirmos todo e qualquer envolvimento emocional.

Apesar das reaçós, o envolvimento emocional acontece para a grande maioria das enfermeiras (9), sendo relatado que o envolvimento é como. se fosse com um filho, principalmente com as crianças que permanecem longo tempo internadas na unidade. Algumas consideram, como aspecto positivo, maior conhecimento da criança através do envolvimento emocional, e consequentemente melhor qualidade de assisténcia; como aspecto negativo, foi comentado que o apego fazia surgir sentimento de "do", o que gerava insegurança, dificultando ainda mais a assistência.

\subsection{Coerência entre a ação e reação}

Outras situaçoes conflitantes ocorrem quando a enfermeira verifica que nem sempre o que faz tem resultado satisfatório. Assim, sentimentos de frustração, culpa, incapacidade e depressão são relatados em decorrência a esses conflitos. Por exemplo: "Não podemos dar tudo que eles precisam e nos sentimos incapazes"; "A causa das minhas frustraçoes é por não estar fazendo mais, sentimento de culpa por se tratar de uma unidade de cuidados intensivos onde as crianças querem brincar e não dá para fazer isso".

\section{Atitude perante a morte}

Poucas fizeram referência direta e espontânea à questão da morte. Falava-se em prognostico fechado, em parada e, ds vezes, tocava-se em "obito", porém, rapidamente e sem maiores detalhes. Por esse motivo incluímos uma questão em relação a ela.

"Como você encara a morte?"

Através das diferentes respostas, foi possivel verificar que a morte é encarada pelas enfermeiras entrevistadas de diversas formas:

\subsection{A morte como uma solução altemativa}

Uma expressiva observação foi feita denotando a dificuldade da convivência diária com a criança grave e o seu sofrimento. Em função dessa situação a morte passa a ter uma outra conotação no dia a dia de uma das enfermeiras. Assim, um dos comentários expressam que "Óbito desgasta mas não é tão chocante quanto o convívio. $O$ duro é conviver com o sofrimento da criança".

Várias enfermeiras (7) consideram a morte como uma solução para a criança em certas condiçoes, ou seja, para as crianças que estão sofrendo, a morte seria um alfvio. Por não termos maiores informaçoes de como se carac- 
teriza o sofrimento dessas crianças, questionamos se a enfermeira envolvida com a criança grave seria levada a considerar a morte como um alívio também para o seu sofrimento e nao somente para o sofrimento da criança.

As seguintes explicaçðes foram dadas para a aceitação da morte de crianças que estão sofrendo: "Vida é qualidade e a medicina valoriza a quantidade"; "Para algumas crianças é bom para o corpo e para a alma"; "Eu acredito em reencarnação".

Apesar das várias colocaçoes feitas para tentar justificar a morte das crianças que sofrem, nenhuma das entrevistadas expressou real compreensão e aceitação da morte como um fato natural; a seguinte expressão "Enfermeira tem que suportar; sabe que UTI é assim" retrata que é um imperativo, para a enfermeira de UTI, "suportar" conviver com a morte, independente da sua atitude para com ela.

\subsection{A morte como uma solução não aceitável}

Das treze enfermeiras entrevistadas, três afirmaram que não aceitam a morte, independentemente das condiçðes de gravidade da doença. Assim, as seguintes afirmaçбes complementam este pensamento:

"É diff́cil, foi uma vida. Sempre acho que haveria mais alguma coisa para ser feita".

"Difícil, quando você não aceita e tem que fazer os pais aceitarem".

A não aceitação da morte algumas vezes mantém relaçđo com algum sentimento de frustração que se associa a ela. As seguintes colocaçðes traduzem essa relação: "Morte em si é frustante; é como se fosse uma derrota"; "Muitas mortes, fico pensando que foi alguma falha da gente".

\subsection{Sentimentos relacionados}

Diferentes sentimentos foram expressados diante da questão da morte, dentre eles medo, frieza, identificados nas afirmaçoes:

"Todo mundo tem medo da morte, muito mais em UTI de criança, por alguma afetividade por ela. No começo, quando as crianças morriam, eu sentia o coração apertado. Depois de tanto tempo, não sinto mais nada. Encaro o fato com um pouco de frieza".

"Nunca houve interferência emocional com a criança ou com a família. Não sei, acho que com o tempo a gente fica fria. É tão rotineiro que preciso tomar cuidado para nao passar a encarar a morte friamente".

Nota-se a credibilidade de que com o tempo a enfermeira se torna "fria", no entanto, é evidente a preocupação desta enfermeira em não permitir que 
isso ocorra, talvez por crer que tal maneira de encarar não lhe é adequada pessoalmente ou profissionalmente.

$\mathrm{Na}$ realidade, em que consistiria o "encarar friamente" a morte para as enfermeiras? Apenas a ausência de reaçôes ou sentimentos ou, então, simplesmente a aceitação da morte, por encará-la como uma etapa natural do processo de vida? Fica aqui mais uma questão para reflexão!

\subsection{Dificuldades relacionadas}

Dentre as dificuldades encontradas pela enfermeira diante da questão da morte, foi mencionada a comunicação da notícia à família. Foi considerado que "a pior hora é a de comunicar a morte aos familiares. É a pior situação por que você tem que passar. Geralmente fica aquele jogo de empurra. E, na realidade, a obrigação é do médico".

Portanto, a enfermeira, por encontrar muitas vezes dificuldade em trabalhar com a morte, acaba preferindo transferir a responsabilidade da comunicação à família para o médico. Tal fato parece predispor ainda mais o distanciamento da enfermeira em relação à família e, conseqüentemente uma oportunidade de prestar assistência mais efetiva à família.

Será que o fato de enfrentar a circunstância da morte, com suas dificuldades, seus problemas, não levaria à maior compreensão da mesma e não despertaria sentimentos menos conflitantes para a enfermeira? Será que a compreensão da morte, como também sua aceitação, levaria a enfermeira a proporcionar melhor assistência à criança moribunda e à sua família? Vamos refletir!

\section{CONCLUSÕES}

Através deste estudo foi possível chegarmos às seguintes conclusర̃es:

- As enfermeiras entrevistadas, que atuam em UTIp, relataram as situações problemáticas ou estressantes decorrentes da sua vivência diária junto à criança grave.

- Foram consideradas situaçōes problemáticas ou estressantes, aquelas que acarretavam: dificuldades no desempenho do papel assistencial e administrativo do enfermeiro; sentimentos de culpa, frustração, incapacidade, impotência, angústia, medo, insegurança e reaçðes emocionais, como crise de choro.

- As fontes de estresse extrínsecas são relativas ao contexto de UTIp, aos aspectos administrativos, à equipe de UTIp, à família e à condição da criança.

- As fontes de estresse intrínsecas são relacionadas à condição pessoal do 
enfermeiro e, ainda, a questão da morte, por envolver crenças e valores intrínsecos à sua formação enquanto pessoa.

Constatamos, ainda, pelo presente estudo, a validade da entrevista semi-estruturada para a obtenção de dados qualitativos; contudo, acreditamos na importância de a ela incorporarmos a dinâmica de grupo e observação para maior aprofundamento das questoes levantadas.

TAKAHASHI, E.I.U. Causes of emotional stress on nurses assisting critically ill children. Rev. Esc. Enf. USP, Sao Paulo, 19(1): 5-20, 1985.

This is a pilot study on the causes of emotional stress on 13 nurses working in Pediatric Intensive Care Units. The Author identified, as extrinsic causes, the objectives and the environment of the units, the relations nurse-members of the working team, the family and the children's critical condition; and, as intrinsic causes, the nurses personal conditions and their attitude towards death.

\section{REFERÊNCIAS BIBLIOGRÁFICAS}

1. CAPALBO, C. Alternativas metodológicas de pesquisa. Trabalho apresentado no III Seminário Nacional de Pesquisa em Enfermagem. Florianópolis, 3 a 6 de abril de 1984.

2. CARNEIRO, A. Comunicaçto enfermeiro/paciente na unidade de terapia intensiva. Estudo interativo do processo de comunicação. Rio de Janeiro, 1982. (Tese apresentada à Escola de Enfermagem Ana Neri).

3. DUNKEL, J. \& EISENDRATH, S. Families in the intensive care unit: their effecton staff. Heart \& Lung, Saint Louis, 12:(3), 258-61, May, 1983.

4. KIMURA, M. Problemas dos pacientes de Unidades de Terapia Intensiva. Estudo comparativo entre pacientes e enfermeiros. Såo Paulo, 1984. (Dissertação de Mestrado - Escola de Enfermagem da USP). 